\title{
Evaluasi Tata Ruang Kawasan Distrik Mariat Kabupaten Sorong
}

\author{
Ayundaningsih Damayanti Girot ${ }^{1}$, Agung Pamudjianto ${ }^{2}$ \\ Universitas Muhammadiyah Sorong
}

\begin{abstract}
Abstrak
Penelitian ini bertujuan untuk mengetahui persebaran tata ruang di Distrik Mariat tahun 2017 dengan menggunakan aplikasi ArcMAP 10.3 serta kesesuaiannya dengan dokumen RTRW Kabupaten Sorong dan Undang-Undang No.26 Tahun 2008 Tentang Penataan Ruang.Penelitian dilakukan dengan metode pengumpulan data antara lain dengan, observasi, studi literatur, pengambilan foto udara, dan dokumentasi. Data yang dihasilkan kemudian diolah dan dianalisis sesuai dengan tujuan penelitian. Dari hasil analisa distribusi penggunaan lahan tahun 2017 dengan menggunakan aplikasi ArcMAP 10.3 kawasan yang telah terbangun 59\% dan kawasan belum terbangun 94,1\% yang masih didominasi dengan hutan. Hal ini menunjukkan persebaran tata ruang di Distrik Mariat belum merata dan masih perlu dioptimalkan lagi pembangunannya. Dengan membandingkan antara hasil digitasi pada aplikasi ArcMAP 10.3 dengan Peta Perencanaan Pola Ruang Kabupaten Sorong menunjukkan kondisi tata ruang saat ini belum sepenuhnya mencapai target yang direncanakan. Juga masih adanya penyimpangan-penyimpangan dalam penataan ruang, menunjukkan peraturan zonasi dalam UU 26 Tahun 2007 telah dilanggar.
\end{abstract}

Keywords : evaluasi tata ruang, penataan ruang, penyimpangan, tata ruang

\section{Pendahuluan Latar belakang}

Perkembangan masyarakat yang ada di Sorong khususnya di daerah Distrik Mariat Kabupaten Sorong tumbuh dengan pesat dari waktu ke waktu. Distrik Mariat merupakan salah satu Distrik yang ada di Kabupaten Sorong. Pemerintah Daerah Distrik Mariat terdiri atas 5 Kampung / Kelurahan. Distrik Mariat yang merupakan pusat pemerintahan Kabupaten Sorong memiliki sebaran penduduk terbesar kedua. Sekitar 15,6 persen penduduk Kabupaten Sorong bermukim di Distrik Mariat, dengan kepadatan penduduk $101 \mathrm{jiwa} / \mathrm{km}^{2}$. (Statistik Daerah Distrik Mariat 2015)

Pertumbuhan penduduk yang pesat memberikan implikasi pada tingginya tekanan terhadap pemanfaatan ruang terkait semakin sempitnya ruang untuk bergerak. Dokumen tata ruang yang memiliki tujuan untuk mengatur ruang agar dapat dimanfaatkan secara efektif dan untuk mencegah terjadinya konflik antar fungsi dalam proses pemanfaatan ruang, serta untuk melindungi masyarakat sebagai pengguna ruang dari bahayabahaya lingkungan. Untuk itu perlu dilakukan evaluasi agar dokumen tata ruang dapat berfungsi sesuai dengan tujuannya. Sebagai sebuah Distrik yang memiliki peraturan daerah, haruslah mampu mengakomodasi berbagai potensi keruangan di wilayah tersebut serta mampu meminimalisasi permasalahan yang ada, sehingga kemakmuran rakyat dapat diwujudkan. Kegiatan evaluasi tata ruang wilayah pada prinsipnya adalah untuk menilai keselarasan antara tujuan, strategi, dan kebijakan yang termuat dalam dokumen RTRW (Rencana Tata * Corresponding author. Telp.: 0853-5442-5302 E-mail addresses: ayundagiroth29@gmail.com
Ruang Wilayah) di Kabupaten Sorong khususnya Distrik Mariat tersebut. Evaluasi tata ruang Distrik didasarkan pada masing-masing pedoman yang disesuaikan dengan masing-masing tujuan kegiatan evaluasi. Melalui kegiatan evaluasi, kesesuaian pemanfataan ruang sesuai dengan fungsi yang telah ditetapkan dapat diwujudkan. Hasil dari evaluasi dapat berupa suatu informasi yang akan dipergunakan sebagai dasar terbentuknya suatu kebijakan sehubungan dengan kemungkinan adanya perbaikan/revisi rencana atau penyusunan rencana

Untuk dapat melakukan evaluasi dan perencanaan secara baik diperlukan ketersediaan data dan berbagai informasi pada daerah yang dikaji. Ilmu pengetahuan dan teknologi khususnya Sistem Informasi Geografis diharapkan mampu mengetahui indeks potensi lahan dengan pemetaan memanfaatkan data-data yang berpengaruh di Distrik Mariat. Oleh karena itu, penulis menggunakan alternatif software GIS dalam pemetaan kawasan Distrik Mariat.

\section{Tujuan Penelitian}

Tujuan dari penelitian ini adalah untuk mengidentifikasi penyebaran tata ruang di Distrik Mariat dan untuk mengidentifikasi kesesuaian Rencana Tata Ruang Wilayah Distrik Mariat dengan penyebaran tata ruang di Distrik Mariat saat ini. 


\section{JURNAL TEKNIK SIPIL : RANCANG BANGUN}

\section{Metodologi penelitian} Lokasi Penelitian

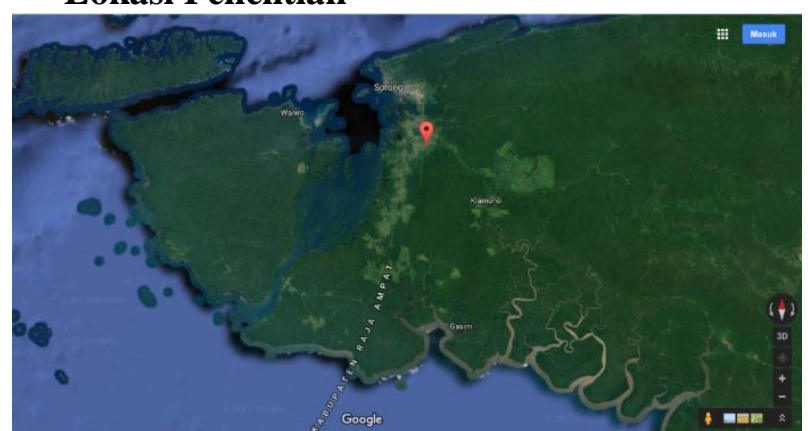

Gambar 1. Lokasi Penelitian Distrik Mariat Kabupaten Sorong

Penelitian dilaksanakan di Distrik Mariat Kabupaten Sorong. Secara geografis, batas wilayah Distrik Mariat adalah:

a. Utara : Distrik Aimas

b. Selatan : Distrik Mayamuk

c. Timur :Distrik Aimas dan Distrik Klamono

d. Barat : Distrik Aimas

Alat-alat yang digunakan pada penelitian ini terdiri dari : drone DJI Phantom 4, smarthphone, dan yang berfungsi untuk mengambil gambar lewat udara kemudian gambar tersebut diolah pada aplikasi GIS (Geographyc Information System).

Pada penelitian ini dilakukan beberapa jenis pengamatan, salah satu yang utama yaitu berapa besar persentase kawasan yang sudah menyimpang dari penggunaan lahan di Distrik Mariat jika di dibandingkan dengan Dokumen RTRW Kabupaten Sorong.

\section{Hasil dan Pembahasan}

\section{Distribusi lahan Distrik Mariat}

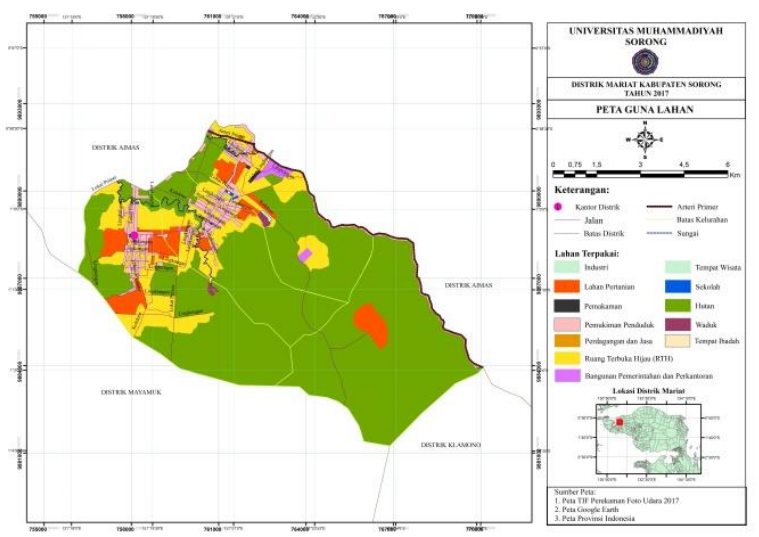

Gambar 2. Peta Distribusi Lahan Distrik Mariat
Dengan melihat peta pada gambar 2, distribusi lahan Distrik Mariat dapat diuraikan pada tabel sebagai berikut:

Tabel 1. Penggunaan Lahan Distrik Mariat berdasarkan analisa digitasi GIS Tahun 2017:

\begin{tabular}{lcc}
\multicolumn{1}{c}{ Jenis Lahan } & $\begin{array}{c}\text { Luas Area } \\
(\mathrm{Ha})\end{array}$ & $\begin{array}{c}\text { Persentase } \\
(\%)\end{array}$ \\
\hline Waduk & 21,5367 & 0,3 \\
perdagangan dan jasa & 3,3552 & 0,04 \\
taman pemakaman & 8,0875 & 0,1 \\
Hutan & 5838,17 & 73 \\
tempat wisata & 4,2668 & 0,05 \\
tempat ibadah & 6,0774 & 0,08 \\
Ruang Terbuka Hijau & 1140,495 & 14 \\
(RTH) & 60,9 & 0,7 \\
bangunan pemerintah & 453,8023 & 5,6 \\
permukiman penduduk & & 6 \\
Pertanian dan & 488,6965 & 6 \\
perkebunan & 0,592 & 0,007 \\
Kesehatan & 8,7021 & 0,11 \\
Sekolah & 1,4668 & 0,02 \\
Industri & $\mathbf{8 0 4 9 , 6 9}$ & $\mathbf{1 0 0 \%}$ \\
Total & & \\
&
\end{tabular}

Dari hasil digitasi, menunjukkan bahwa sebagian besar lahan Distrik Mariat merupakan hutan, yaitu seluas 5838,17 Ha atau 73\% dari luas Distrik Mariat.

Tabel 2. PenggunaaDistribusi lahan Distrik Mariat berdasarkan kawasan terbangun dan tidak terbangun:

\begin{tabular}{ccc}
\hline Guna Lahan & $\begin{array}{c}\text { Luas Area } \\
(\mathrm{Ha})\end{array}$ & Persentase \\
\hline $\begin{array}{c}\text { Kawasan } \\
\text { Terbangun }\end{array}$ & 474,5 & $5,9 \%$ \\
$\begin{array}{c}\text { Kawasan Tidak } \\
\text { Terbangun } \\
\text { Total }\end{array}$ & 7575,2 & $94,1 \%$ \\
& $\mathbf{8 0 4 9 , 7}$ & $\mathbf{1 0 0 \%}$
\end{tabular}

Dari tabel 2 dapat terlihat bahwa sebagian besar kawasan Distrik Mariat adalah lahan yang belum terbangun, yaitu seluas $7575,2 \mathrm{Ha}$ atau $94,1 \%$ dari luas Distrik secara keseluruhan. 


\section{Evaluasi}

Distrik Mariat pada Peta Rencana Pola Ruang Tahun 2011-2031 diperuntukkan sebagai Kawasan Perkotaan Aimas (Kawasan Terbangun) dengan jumlah $71 \%$ dan Kawasan Perkebunan Rakyat sejumlah 29\% dari Luas Distrik keseluruhan.

Pada penelitian tahun 2017 ini didapatkan hasil Kawasan Perkotaan Aimas 32,3\% dan Kawasan Perkebunan Rakyat 32,3\%. Secara rinci dapat dilihat pada Tabel 3 berikut.

Tabel 3. Perbandingan Penggunaan Lahan Distrik Mariat antara Peta Rencana Pola Ruang dan pada Tahun 2017

\begin{tabular}{ccc}
\hline \multirow{3}{*}{ Jenis } & Peta & Hasil \\
& Rencana & Digitasi \\
& Pola Ruang & GIS 2017 \\
\hline
\end{tabular}

$\begin{array}{ccc}\begin{array}{c}\text { Kawasan Perkotaan } \\ \text { Aimas }\end{array} & 71 \% & 32,3 \% \\ \begin{array}{c}\text { Kawasan Perkebunan } \\ \text { Rakyat }\end{array} & 29 \% & 6 \%\end{array}$

Pasal 36, Undang-Undang Nomor 26 Tahun 2007 tentang Penataan Ruang, menyebutkan tentang peraturan zonasi. Pada Peraturan zonasi untuk sistem jaringan prasarana wilayah huruf $E$ "Peraturan zonasi pada jaringan sarana prasarana energi" nomor 2 dijelaskan bahwa pelarangan untuk pemanfaatan ruang bebas di sepanjang jalur transmisi sesuai dengan ketentuan peraturan perundang-undangan. Namun peraturan tersebut tidak berbanding lurus dengan kondisi nyata di lapangan. Hal ini terlihat dari beberapa BTS (Base Transceiver Station) di Disrik Mariat yang jaraknya dengan bangunan kurang dari 30 meter. Padahal peraturan untuk jarak aman menara yang tingginya di atas 45 meter, jarak dari bangunan perumahan adalah minimal 30 meter.

\section{V. Kesimpulan dan Saran}

\section{Kesimpulan}

Berdasarkan hasil penelitian yang telah dilaksanakan penulis dapat menyimpulkan bahwa Persebaran penggunaan lahan di Distrik Mariat belum tersebar secara merata, hal ini terihat dari jumlah kawasan yang belum terbangun yang masih lebih luas daripada kawasan yang telah terbangun pada Distrik Mariat, kawasan belum terbangun masih didominasi oleh hutan dan Lahan Terbuka Hijau (RTH) dan Penyebaran Penggunaan Lahan di Distrik Mariat sepenuhnya sesuai dengan Perencanaan yang ada dalam Dokumen RTRW dan Undang-Undang Nomor 26 Tahnun 2007 Tentan Rencana Penataan Ruang. Hal ini ditunjukkan dengan masih ada program / rencana yang belum terealisasi tahun 2017 dan masih terdapat penyimpangan pada tata ruangnya.

\section{Saran}

Untuk memperoleh hasil yang lebih baik dalam melaksanakan penelitian ini, dikemukakan saran kepada Pemerintah harus lebih mengoptimalkan pemanfaatan potensi wilayah di Daerah masih jarang penduduk agar persebaran pembangunan menjadi merata di Distrik Mariat. Terutama pada aspek sarana dan prasarana, juga pembangunan infrastruktur sosial agar berdampak optimal terhadap pengembangan sumber daya manusia dan Pembangunan di Daerah yang masih jarang penduduk dan Pemerintah dapat memanfaatkan data pengindraan jauh untuk meminimalisir penyimpangan yang terjadi akibat pemanfaatan ruang.

\section{Daftar pustaka}

Badan Pusat Statistik Kab.Sorong. Statistik Daerah Distrik Mariat Tahun 2015. ISSN : 23021969

Direktorat Jenderal Penataan Ruang Kementerian Pekerjaan Umum, (2009). Permen 16/PRT/2009, Pedoman Penyusunan Rencana Tata Ruang Wilayah Kota.

Ibnu, R. (2006, June 26). Pemerintah Ajak Publik Bahas Menara Telekomunikasi.

Republik Indonesia. 2007. Undang-Undang No.26 Tahun 2007 tentang Penataan Ruang.

Rancangan Peraturan Daerah. Rencana Tata Ruang Wilayah (RTRW) Kabupaten Sorong Tahun 2010-2030. Kbupaten Sorong: Kementerian PUPR 